\title{
Genetic diversity and population structure of Pseudomonas savastanoi, an endemic pathogen of the Mediterranean area, revealed up to strain level by the MLVA assay
}

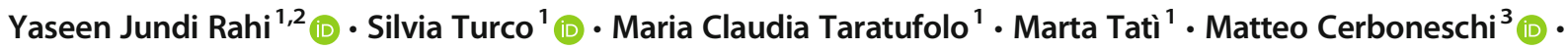 \\ Stefania Tegli ${ }^{3}$ (D) Franco Valentini ${ }^{2}$ (D) - Annamaria $D^{\prime}$ Onghia $^{2} \cdot$ Nicola Sante lacobellis $^{4}$. \\ Giorgio Mariano Balestra ${ }^{1}$ (D) - Angelo Mazzaglia ${ }^{1}$ (D)
}

Received: 12 December 2019 / Accepted: 3 June 2020

(C) Società Italiana di Patologia Vegetale (S.I.Pa.V.) 2020

\begin{abstract}
Pseudomonas savastanoi is a bacterial species included in the Pseudomonas syringae complex. It is further sub-typed in pathovars which are the causal agents of a group of diseases of woody plants, such as the "knot disease" on olive and oleander and the bacterial canker on ash. Given its long-established presence in the Mediterranean area, the pathogen causing the aforementioned diseases can be considered endemic. Here, an MLVA approach was developed to assess the genetic relationships among and within those pathovars, with a specific focus on $P$. savastanoi pv. savastanoi. By analyzing the genome of the $P$. savastanoi pv. savastanoi strain NCPPB 3335 (accession $\mathrm{n}^{\circ}$ CP008742), 14 Tandem Repeat (TR) loci were identified and the corresponding primers were designed and used for the amplification of genomic DNAs from 84 strains belonging to Pseudomonas savastanoi pathovars. Data were analyzed using different approaches, such as hierarchical clustering, STRUCTURE, and k-means clustering with DAPC to evaluate the effectiveness of the assay in describing pathovars and population structure of the pathogen. Results reveal a very complex articulation of genetic relationships, as expected from a long-time evolving pathogen, while providing the possibility to discriminate the pathovars between each other. At intra-pathovar level, the MLVA assay clusters isolates mainly according to their hosts and geographic origin. This resulted particularly useful in the identification and tracking of $P$. savastanoi populations at local level.
\end{abstract}

Keywords Knot disease $\cdot$ VNTR $\cdot$ MLVA $\cdot$ DAPC $\cdot$ Population structure

\section{Introduction}

The term "knot disease" in plant pathology describes the excessive growth of plant tissues or organs that leads to

Angelo Mazzaglia

angmazza@unitus.it

1 Department of Agricultural and Forestry Sciences, University of Tuscia, Via S. Camillo de Lellis snc, 01100 Viterbo, Italy

2 CIHEAM-Mediterranean Agronomic Institute of Bari, Via Ceglie 9, 70010 Valenzano, Ba, Italy

3 Agrifood Production and Environmental Sciences (DISPAA), University of Florence, Piazzale delle Cascine 18, 50144 Florence, Italy

4 School of Agricultural, Forestry, Food and Environmental Sciences, University of Basilicata, Viale dell'Ateneo Lucano, 85100 Potenza, Italy hyperplastic and/or hypertrophic masses in the shape of tumors or knots. These formations can be clearly observed on the aerial parts of diseased plants mostly on the woody parts of the plant such as stem, branches, or twigs and, more rarely, on leaves and fruits. Generally, the disease is caused by the Gram-negative bacterium Pseudomonas savastanoi (Janse 1982; Iacobellis 2001; Ramos et al. 2012; Buonaurio et al. 2015), which is a monomorphic pathogenic gamma-proteobacterium species belonging to the genomospecies 2 of the Pseudomonas syringae complex (Gardan et al. 1992). To date, six pathovars have been described within this species. Pseudomonas pv. savastanoi (Gardan et al. 1992), pv. fraxini, pv. nerii (Janse 1982), and pv. retacarpa (Garcia De Los Rios 1999) attack members of different plant families including Oleaceae (Olea europaea, Jasminum officinalis, Forsythia spp., Phyllirea spp., and Ligustrum japonicum), Fabaceae (Retama), Rhamnaceae (Rhamnus spp.), Myrtaceae (Myrtus communis), Apocinaceae (Nerium oleander, Mandevilla sanderi), and Lythraceae 
(Punica granatum) (Bradbury 1986; Iacobellis et al. 1998; Marchi et al. 2011; Moretti et al. 2017). The pathovar phaseolicola (Gardan et al. 1992) is responsible for the halo blight of beans (Phaseolus vulgaris L.) (Völksch and Weingart 1997), with the exception of some strains of pv. phaseolicola that attack mulberry (Dworkin 2006), while pv. glycinea (Young 1978) is the causal agent of bacterial halo blight of soybean (Glycine max) and is restricted to this host species. Pseudomonas savastanoi pathovars are classified based on host range and genetic information (Mugnai et al. 1994). Early studies have focused on the differentiation and clarification of different pathovars using an array of morphological, serological, physiological, nutritional, biochemical, numerical taxonomy and DNA-DNA hybridization (Janse 1982; Gardan et al. 1992). These methods have shown some limitations over time, especially when differentiation or relatedness are required at strain level (Bennasar et al. 2010). The movement of goods around the world and the open borders have facilitated the diffusion of plant diseases through the movement of pathogens into new areas. Furthermore, climate change has helped the emergence or re-emergence of new pathogens, which negatively affect the food production (Grünwald and Goss 2011). Therefore, population genetic analyses are necessary to understand how a pathogen emerges and adapts to the environment (Grünwald et al. 2017). Indeed, the comprehension of population genetics has been enhanced by coalescent theory, computational methods and molecular biology, which have initiated the genomic era (Hartl and Clark 2007).

Only a few tools have been developed to investigate in detail and understand the genetic diversity among the strains of Pseudomonas savastanoi pathovars. Therefore, there is a necessity for a reliable method that can accurately discriminate between bacterial strains for crop surveillance, outbreak investigation and for the study of the evolution of plant pathogens in order to establish disease control strategies (Cesbron et al. 2014). Molecular typing methods are fast and powerful tools that allow to distinguish between closely related strains in an epidemiological survey, to determine relationships among the strains and to track their origin and pathways of spread. Molecular approaches can also help understanding evolution, host adaptation, and genetic diversity (Van Belkum et al. 2001; Scortichini et al. 2004; Wolska and Szwe 2012). Furthermore, they could reveal biological features of the pathogen that can affect virulence, pathogenicity, and host specificity, helping us to set up sustainable control measures (Tibayrenc 2005; Vinatzer et al. 2014).

The Restriction fragment Length Polymorphism (RFLP) has been one of the first molecular approaches to investigate Pseudomonas savastanoi; it has been used on a group of Italian strains from olive, oleander and ash trees for the evaluation of the differences among these strains (Sisto et al. 2002). PCR and random amplification of polymorphic DNA (RAPD) have also been used to evaluate associations between strains of Pseudomonas savastanoi pathovars and their geographical distribution (Scortichini et al. 2004; Krid et al. 2009). Furthermore, fluorescent Amplified Fragment Length Polymorphism (f-AFLP) analysis has been used to appreciate genetic variability among a pool of representative strains from different olive regions around the world (Sisto et al. 2007). In Spain, the genetic diversity of Pseudomonas savastanoi pv. savastanoi has been investigated using the Insertion element (IS53) as typing method (López et al. 2008).

Despite the good results obtained, these methods remain time-consuming and poorly reproducible, limiting severely the possibility to compare results across laboratories (Cangelosi et al. 2004; Zhao et al. 2012). MLST is one of the most acknowledged methods for subtyping bacterial plant pathogens, though Sanger sequencing is always required. The results obtained by MLST were reported in agreement with those by DNA-DNA hybridization in $P$. syringae complex (Cinelli et al. 2014). More recently, Moretti and colleagues studied the genotypic diversity of Mediterranean populations using repetitive element palindromic PCR (rep-PCR) and MultiLocus Sequence Typing (MLST) of four housekeeping genes, namely gap, gltA, gyrB, and rpoD (Moretti et al. 2017). However, the sequences of the housekeeping genes usually show scarce diversity between individuals at subspecies level, which could result in failure when the aim is to resolve the evolutionary patterns of the bacterial populations (Achtman 2008), or to understand the populations pattern of highly homogeneous bacterial pathogens (Grissa et al. 2008).

In recent years Whole Genome Sequencing (WGS) and Single Nucleotide Polymorphism (SNPs) have been widely applied on many plant pathogenic bacteria, including Pseudomonas savastanoi pathovars (Pérez-Martínez et al. 2008; Rodríguez-Palenzuela et al. 2010; Moretti et al. 2014; Bartoli et al. 2015). These methods provide details about the entire genome sequences, but their cost is high; they also require advanced next-generation sequencing technologies, and most of all, high knowledge and computational skills, as well as devoted infrastructural facilities (Poulin et al. 2015; Davis et al. 2016).

MLVA (Multiple Loci Variable number of tandem repeat Analysis) is a very efficient typing technique. This molecular method is based upon the calculation of Variable copy Numbers of Tandem Repeats (VNTR). These tandemly repeated sequences (TR loci) have been found scattered throughout the prokaryotic and eukaryotic genomes (van Belkum et al. 1998; Lindstedt 2005); they are among the most variable regions in bacterial genomes, thus having the potential to resolve the genetic diversity of monomorphic pathogens. TRs occur in the genome due to a mismatch in DNA strands during replication (slipped-strand mispairing) or DNA recombination error (Gemayel et al. 2010; Vieira et al. 2016). TRs have been found to play an important role in bacterial adaption (Saunders et al. 2000), phase variation (Gemayel 
et al. 2010), and speed of loss gene disorder (Rocha 2003); they also facilitate evolutionary changes (Oliveira et al. 2006; Reinar et al. 2018), as well as genome plasticity and variation (Treangen et al. 2009). In order to calculate these TRs, PCR primers are designed in the conserved regions around these TRs. Then, the differences in the dimension of the amplicons among the strains are measured by capillary electrophoreses and converted in integers by detracting the right and the left flanking regions from the PCR amplicons, and dividing the remaining length by the size of the corresponding repeat unit in that locus. The numeric data obtained can be exchanged among laboratories directly or via public MLVA database (Grissa et al. 2008).

The discriminatory power of MLVA is based on the differences in the number of repeats in each of several loci, as generated by amplification of genomic DNA, resulting in a high level of polymorphism (Li et al. 2009). Moreover, MLVA is a fast procedure for monitoring recent, local outbreaks of bacterial pathogens, providing insights about the relationships at microevolutionary level (Ee et al. 2017).

MLVA methodology was primarily developed for human (van Belkum et al. 1997; Noller et al. 2003; Marsh et al. 2006) and animal bacterial pathogens (Le Flèche et al. 2006). Successively, it was applied for the first time on the plant pathogenic bacteria Xylella fastidiosa (Della Coletta-Filho et al. 2001) and, after that, it has been widely used to investigate bacterial plant diseases, as in Xanthomonas citri pv. citri (Vernière et al. 2014; Pruvost et al. 2014), Xanthomonas arboricola pv. pruni (Bergsma-Vlami et al. 2012), Pseudomonas syringae pv. maculicola and Pseudomonas syringae pv. tomato (Gironde and Manceau 2012), Xanthomonas oryzae pv. oryzicola (Zhao et al. 2012), Ralstonia solanacearum (N'Guessan et al. 2013), Clavibacter michiganensis subsp. michiganensis (Zaluga et al. 2013), Erwinia amylovora (Bühlmann et al. 2014), Pseudomonas syringae pv. actinidiae (Ciarroni et al. 2015), and Ralstonia solanacearum (Guinard et al. 2017).

In this study, we identified for the first time VNTRs loci and designed an MLVA assay on Pseudomonas savastanoi, to be analyzed by hierarchical clustering, k-means clustering and STRUCTURE software. The aim was to recognize pathovars and understand genetic relationships between populations within a wide collection of strains including worldwide isolates, isolates from an olive orchard from one region and a single tree of the same orchard.

\section{Materials and methods}

\section{Bacterial strains and growth conditions}

The study was carried out on a group of 84 strains of Pseudomonas savastanoi representative of the pathovars savastanoi, neri, fraxini, retacarpa, and phaseolicola. Sixtytwo strains were obtained from the DAFNE collection of the University of Tuscia in Viterbo, (Italy) and from the CIHEAM collection in Bari (Italy). Twenty-four additional samples were isolated from an olive orchard in Viterbo; 14 of them were collected randomly in the orchard, while the remaining 10 were obtained from a single tree. The bacteria were grown on King's B medium $(\mathrm{KB})$ at $28{ }^{\circ} \mathrm{C}$ for $48 \mathrm{~h}$ before DNA extraction.

\section{Genomic DNA extraction}

Genomic DNA was extracted from freshly grown colonies using the QIAGEN kit (GmbH, Germany) following the manufacturer instruction. DNA quantification was obtained by a Qubit Fluorometer (Invitrogen, Life Technologies Italia, Monza, Italy), then its concentration was adjusted to $40 \mathrm{ng} /$ $\mu l$ with TE (10mMTris-HCl, $1 \mathrm{mM}$ EDTA) buffer at $\mathrm{pH} 8.0$, before storage at $-20 \mathrm{C}^{\circ}$ until use. The identity of all the strains as Pseudomonas savastanoi was confirmed through iaaL gene amplification (Penyalver et al. 2000).

\section{Tandem repeats identification and design of VNTR primers}

The complete genome sequence of the Pseudomonas savastanoi pv. savastanoi strain NCPPB 3335 (GenBank accession number CP008742) was analyzed to ascertain the presence of candidate VNTR loci using Tandem Repeats Finder program (TRF; https://tandem.bu.edu/trf/trf.html) (Benson 1999) with the following parameters: tandem repeat range from 50 to $1000 \mathrm{bp}$, repeat unit length from 5 to $300 \mathrm{bp}$ and identity higher than $80 \%$ between the copies of the tandem repeat array.

The VNTRs matching the predicted polymorphism size among savastanoi, neri, and fraxini pathovars were selected. To confirm the presence of these regions in all the available WGS sequences, both the right and left flanking regions of about $100 \mathrm{bp}$ each were tested by BLAST (Altschul et al. 1990). Primer pairs were designed by Primer3plus software (http://www.bioinformatics.nl/cgi-qbin/primer3plus/ primer3plus) in the flanking regions of each selected tandem repeat.

\section{PCR amplification, agarose gel electrophoresis}

The selected VNTR loci were amplified using a C1000 Thermal Cycler (Bio-Rad, USA). Each PCR reaction mix contained $12.5 \mu \mathrm{L} 2 \mathrm{X}$ GoTaq ${ }^{\circledR}$ master mix (Promega, Madison, USA), $9.5 \mu \mathrm{L}$ nuclease-free water and $1 \mu \mathrm{L}$ (40 ng) of template DNA, and $1 \mu \mathrm{L}$ of each primer corresponding to $10 \mu \mathrm{M}$ concentration, in a final volume of $25 \mu \mathrm{L}$. All the PCR reactions were run with an initial 
denaturation step of $5 \mathrm{~min}$ at $94{ }^{\circ} \mathrm{C}$ followed by 35 cycles at $94{ }^{\circ} \mathrm{C}$ for $30 \mathrm{~s}, 50{ }^{\circ} \mathrm{C}$ to $67^{\circ} \mathrm{C}$ (depending on the primer pair) for $30 \mathrm{~s}$ at $72^{\circ} \mathrm{C}$ for $2 \mathrm{~min}$ with a final extension step of $10 \mathrm{~min}$ at $72{ }^{\circ} \mathrm{C}$. PCR products were separated on $1.5 \%$ agarose gels and visualized under UV upon Gel Red® Nucleic Acid to confirm positive amplification. A random selection of samples underwent Sanger sequencing to check the exactness of the number of tandem repeats calculation.

\section{VNTR analysis by capillary electrophoresis}

The amplicons were analyzed using a QIAxcel multi-capillary electrophoresis system (QIAGEN, Milan, Italy). A DNA High-Resolution gel cartridge and the OM800 method were used to estimate amplicons sizes below $600 \mathrm{bp}$, with the following run parameters: $10 \mathrm{~s}$ of sample injection time; $5 \mathrm{kV}$ of sample injection voltage; $3 \mathrm{kV}$ of separation voltage for $700 \mathrm{~s}$ of separation time. The OM500 method was instead used for amplicons larger than $600 \mathrm{bp}$, with higher separation voltage $(5 \mathrm{kV})$ and shorter separation time $(500 \mathrm{~s})$. The final results were analysed and interpreted using the Screen gel software (QIAGEN), which estimates both size and concentration of the amplicons.

\section{Data analysis}

The data matrix containing the tandem repeats numbers for 15 different loci, among 84 isolates, was imported into $\mathrm{R}$ version 3.4.4 (R Core Team 2018) and transformed into a genind object using the R package adegenet 2.1.1 (Jombart 2008). All the analyses of population structure and genetic diversity were performed using $\mathrm{R}$ packages poppr, version 2.8.1 (Kamvar et al. 2014, 2015), adegenet 2.1.1 (Jombart 2008), and ade4 version 1.7-13 (Dray and Dufour 2007). The poppr clonecorrect() function was used to discard duplicated genotypes and the biases they could induce, as well as to remove the clones while collapsing them into unique multilocus genotype (MLGs). To evaluate if the number of loci was enough to describe the diversity between individuals, the genotype_curve() function of the poppr package was used with 1000 random samplings.

A hierarchical clustering analysis was performed with hclust() function of the package stats (R Core Team 2018) to reveal the population structure, using Bruvo's distance and UPGMA algorithm. The result was visualized as a dendrogram with the $\mathrm{R}$ package factoextra version 1.0.5 (Kassambara and Mundt 2017). Furthermore, poppr bruvo.boot() function was used to calculate Bruvo's distance with bootstraps with a cut-off threshold of 80 .

The population structure was also evaluated using STRUCTURE software version 2.3.4 with $\mathrm{K}$ number set from 2 to 10 and 10 iteration runs per each K (Pritchard et al. 2000). Additionally, Evanno method was applied to obtain the optimal $\Delta \mathrm{K}$ estimation (Evanno et al. 2005). STRUCTURE results were combined using CLUMPP algorithm through the clumppExport() function of the same package and visualized with the function plot $Q()$.

Also, a Discriminant Analysis of Principal Components (DAPC) was carried out using the R package adegenet (Jombart et al. 2010). The Bayesian Information Criterion (BIC) and the function xval.Dapc() were used to evaluate the number of clusters to be selected and the correct number of principal components to retain.

\section{Results}

The search within the Pseudomonas savastanoi pv. savastanoi genome sequence NCPPB 3335 performed via TRF program resulted in about 110 candidate VNTR loci. The comparison of the candidate loci against the WGS sequences of other $P$. savastanoi strains available in NCBI showed that less than $30 \%$ of these loci varied in size. A total of 20 candidate VNTR loci having a match percentage higher than $90 \%$ were selected and respective primer pairs were consequently designed. The TRs characteristics, the sequence of the primers, the position of the amplicon along the reference genome of NCPPB 3335 and the putative gene functions, if relevant, are summarized in Table 1 . The 20 VNTRs loci were amplified on the 84 isolates for a total of 1680 reactions and the amplicons were separated via the QIAxcel multi-capillary electrophoresis system. The entire procedure was repeated twice for each sample. Five out of 20 loci gave multiple products or lacked reproducibility, which prompted their exclusion from further analysis.

A total number of 129 alleles were detected in all the final 15 VNTR loci, ranging from only 2 alleles for TRsav8 and TRsav17 loci, to a maximum of 30 alleles in the locus TRsav16 (data not shown).

The final data matrix containing the number of repeats, imported on $\mathrm{R}$ and clone corrected, resulted in 84 individuals collapsing into 78 unique multilocus genotypes (MLGs), adequate to describe the diversity between individuals, as shown by the genotype accumulation curve in Fig. 1 (Kamvar et al. 2015). The $\operatorname{poppr()}$ function from the same $\mathrm{R}$ package was used to obtain the diversity indexes reported in Table 2. More specifically, besides the number of individuals (N) and MLG per population, the expected MLG (eMLG) represents the number of MLG at the lowest sample size. Simpson's Index $(\lambda)$, which is a measure of the probability that two randomly selected genotypes are different from each other, indicates that the Pseudomonas savastanoi pv. savastanoi clade, the more populated in the data set, resulted to be also the most divergent. Genotype Evenness (E.5) measures the genotype abundances within a population. In this case, Pseudomonas savastanoi pv. fraxini and Pseudomonas savastanoi pv. 
Table 1 Characteristics, putative gene function and primers used for the TRs analyzed in this study

\begin{tabular}{|c|c|c|c|c|c|}
\hline $\begin{array}{l}\text { Name of } \\
\text { TRs }\end{array}$ & $\begin{array}{l}\text { TR unit length } \\
\text { (bp) }\end{array}$ & $\begin{array}{l}\text { TRs } \\
\text { length }\end{array}$ & start- end & Gene function & Primers \\
\hline TRsav1 & 9 & 158 & $\begin{array}{l}995,987 \\
996,340\end{array}$ & Hypothetical protein & $\begin{array}{l}\text { FR:ATTTCCTGAGCGTCCTGTGT } \\
\text { RV:ATTAAAGTGTTGATTCTTTC }\end{array}$ \\
\hline TRsav2 & 6 & 152 & $\begin{array}{l}1,659,360 \\
1,659,565\end{array}$ & Tellurium resistance protein Tera & $\begin{array}{l}\text { FR: CTTGAACCGCTGGCAAAA } \\
\text { RV:CCGAAACCGGCGCTGGATTT }\end{array}$ \\
\hline TRsav3 & 7 & 166 & $\begin{array}{l}1,988,604 \\
1,990,085\end{array}$ & Glycosyl transferase & $\begin{array}{l}\text { FR: ATCTGGTGGGTTTCATGACC } \\
\text { RV: CTCTGCATAATCGTATCCCT }\end{array}$ \\
\hline TRsav6 & 7 & 193 & $\begin{array}{l}935,627 \\
938,149\end{array}$ & Flavodoxin & $\begin{array}{l}\text { FR:CTGGTGGATAACCGTCAGGT } \\
\text { RV:AGCTGATCGAGCAAGGACGT }\end{array}$ \\
\hline TRsav7 & 8 & 179 & $\begin{array}{l}2,469,543 \\
2,469,753\end{array}$ & Transposase & $\begin{array}{l}\text { FR: CTTGCCCATCTTGTCGACTT } \\
\text { RV:GGCAACGCGCAGGCTCTGGA }\end{array}$ \\
\hline TRsav8 & 6 & 153 & $\begin{array}{l}5,324,874 \\
5,325,044\end{array}$ & DNA topoisomerase IV subunit A & $\begin{array}{l}\text { FR: CGACCGTGAACAGAACTG } \\
\text { RV: ACCGCCAGATCGGTCACATA }\end{array}$ \\
\hline TRsav10 & 8 & 169 & $\begin{array}{l}2,528,494 \\
2,528,694\end{array}$ & 4-hydroxy-tetrahydrodipicolinate synthase & $\begin{array}{l}\text { FR: GATGCTGGCTGAGGGTTG } \\
\text { RV: GCGCAGATGCCCTGTCGATC }\end{array}$ \\
\hline TRsav11 & 6 & 175 & $\begin{array}{l}2,659,925 \\
2,660,123\end{array}$ & $\begin{array}{l}\text { heme } A B C \text { transporter ATP-binding protein } \\
\quad \text { CcmA }\end{array}$ & $\begin{array}{l}\text { FR: GCTCAATCTGTTGTGGGTTG } \\
\text { RV:CTGCTGCCCGGCCGACAAGG }\end{array}$ \\
\hline TRsav13 & 24 & 130 & $\begin{array}{l}1,219,712 \\
1,219,889\end{array}$ & Hypothetical protein & $\begin{array}{l}\text { FR: AAGATTTGGTACGCCAGCAG } \\
\text { RV: GGTTTTACAGGTGGCCTCAC }\end{array}$ \\
\hline TRsav15 & 8 & 194 & $\begin{array}{l}134,818 \\
135,075\end{array}$ & unknown & $\begin{array}{l}\text { FR: TTTGATGATCAGCCTTCGTG } \\
\text { RV: GGCGCGATGATGGAGCGG }\end{array}$ \\
\hline TRsav16 & 6 & 133 & $\begin{array}{l}259,976 \\
260,396\end{array}$ & Hypothetical protein & $\begin{array}{l}\text { FR: GTCAGATGCTTTTGGCTTGA } \\
\text { RV:TGGAGATCCCTTTATTAATG } \\
\quad \text { AC }\end{array}$ \\
\hline TRsav17 & 6 & 187 & $\begin{array}{l}495,079 \\
495,294\end{array}$ & Phosphodiesterase & $\begin{array}{l}\text { FR: ACCTATGGCGTGGTCGATAC } \\
\text { RV: TTGTGTCGATCGTCATGATT }\end{array}$ \\
\hline TRsav18 & 9 & 157 & $\begin{array}{l}996,131 \\
996,323\end{array}$ & Hypothetical protein & $\begin{array}{l}\text { FR: ATAACCAGTCCGCGAGCTAA } \\
\text { RV: TGTTTCATGAGCTAGAGAAA }\end{array}$ \\
\hline TRsav19 & 7 & 173 & $\begin{array}{l}1,990,097 \\
1,990,297\end{array}$ & GDP-mannose dehydrogenase & $\begin{array}{l}\text { FR: TAAGTCAGTTGCGAGCCTCA } \\
\text { RV: GACTCCCGAAGGCA } \\
\quad \text { AGCGCG }\end{array}$ \\
\hline TRsav20 & 8 & 149 & $\begin{array}{l}3,346,599 \\
3,346,771\end{array}$ & unknown & $\begin{array}{l}\text { FR: GGTTCACTGCATCAAACCAG } \\
\text { RV: ATGGGCGAGGGTTGCTGTTC }\end{array}$ \\
\hline
\end{tabular}

phaseolicola resulted to be the ones with the highest genotype diversity. Finally, the highest Nei's diversity, which is the average genetic diversity per locus, also defined as expected heterozygosity (Hexp), was measured for Pseudomonas savastanoi pv. savastanoi.

\section{Hierarchical clustering}

The hierarchical clustering performed using Bruvo's distance and UPGMA as the agglomerative algorithm, generated the dendrogram in Fig. 2, where only bootstrap values higher than $80 \%$ are shown. According to the intrinsic nature of the method, the number of clusters depends on the choice of the threshold distance, and thus, in this first step of the analysis, the organization of the groups was observed as it is, keeping the bootstrap values as key points for the validation.

In the dendrogram, the two Pseudomonas savastanoi pv. phaseolicola strains emerge as very similar to each other, and contemporaneously the most distant from all the other strains with a $100 \%$ bootstrap support, thus representing the outgroup for the analysis. Regarding the other pathovars, all the Italian strains belonging to the pathovar nerii clustered together; the only exception being the strain ITM305, that was instead isolated in California, USA, back in 1981. The same occurs for the strains of pathovar fraxini, which again form a clear cluster without exclusion. A single strain (SUPP3085) isolated from olive in Japan and the only strain belonging to the pathovar retacarpa are loosely related to this cluster. Then, the 


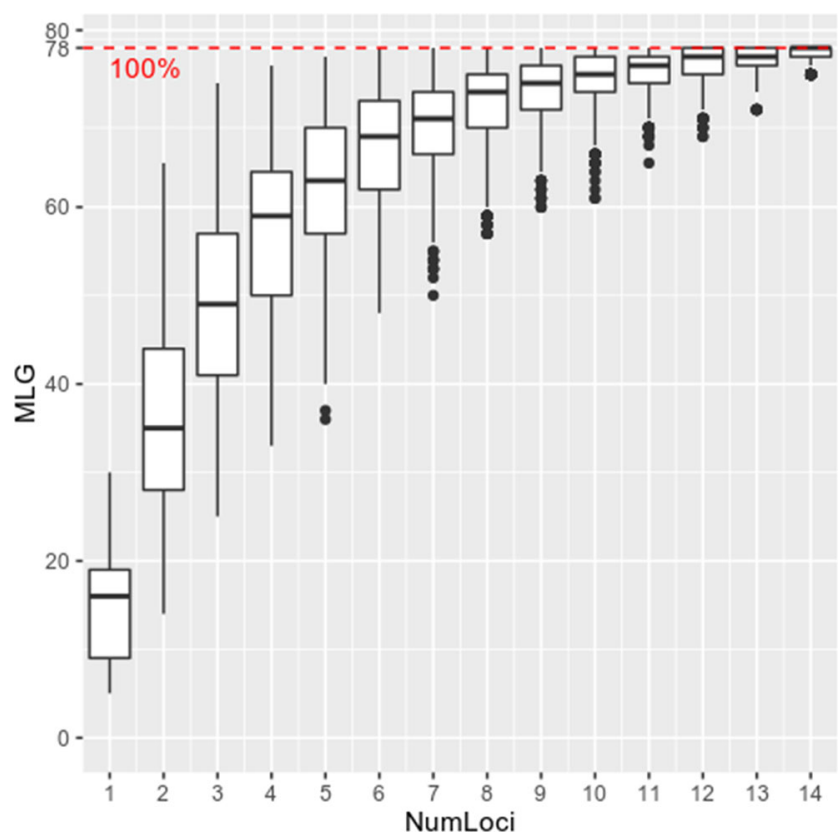

Fig. 1 Genotype accumulation curve for 84 isolates of Pseudomonas savastanoi. The $\mathrm{x}$-axis represents the number of loci that was randomly sampled 1000 times up to (n-1) loci while the y-axis represents the number of multilocus genotypes observed up to 78 MLGs in the dataset. The dashed lines at the plateau indicate that enough number of loci where used to discriminate between individuals

numerous strains belonging to the pathovar savastanoi show a quite scattered distribution along the dendrogram, providing for a large genetic variability. Nonetheless, several clusters are recognizable, often in clear relationship with the plant host, when it is different from olive, or with their geographical origin. The cluster "savast. C)", formed by strains isolated from Jasminum, or the cluster "savast. G)" whose strains were obtained from Ligustrum, are examples of liaison to host plant species, whilst geographic affinities referable to the country of isolation are evident for clusters "savast. B)"-Albania, "savast. E)"-Portugal, "savast. F)"-Morocco, "savast. H)"-Syria, and "savast. C)"-California. An independent position in the dendrogram is coherently taken by single strains from Japan (SUPP3129 and SUPP3085) and from Tunisia (TN177). Regarding the Italian strains, it is worth noting the independent grouping of isolates from a single orchard in Viterbo
Fig. 2 Dendrogram of 84 Pseudomonas savastanoi strains based on Bruvo's distance and UPGMA as algorithm; the bootstrap values (for 1000 replicates) are given at the nodes

(Italy), among which those isolated from a single tree furtherly grouped together forming an additional subcluster.

\section{STRUCTURE analysis}

The analysis of MLVA data using STRUCTURE software was run with $\mathrm{K}$ ranging from 2 to 12 and 10 independent iteration runs for each $\mathrm{K}$. The results were imported in $\mathrm{R}$ environment and Evanno's method was applied using evannoMethodStructure() function in the $\mathrm{R}$ package pophelper (Francis 2017) to obtain the optimal K value of 9 , as showed in Fig. 3.

Thus, the 10 iterated results from $\mathrm{K}=9$ were combined and merged using CLUMPP and are shown in Fig. 4, where the percentage of assignment to each of the 9 groups is represented in the proportion of respective colors in individual bars. The previous hierarchical clustering is confirmed for the pathovar fraxini (Cluster 3 - dark pink), including the exception of strain NCPPB1006, and the pathovar nerii (Cluster1 orange), in which, however, two strains (ITM510 and PVBa219-2) show a deep admixture of possible clusters, as well as for the strain ITM305, already described out of this cluster in hierarchical clustering. It has to be noted that the two phaseolicola strains did not show a clear fitting to a single cluster as in the previous analysis. The STRUCTURE grouping instead reveals a strong signal of independence for the savastanoi strains from Viterbo (Cluster 7 - black), from Greece (Cluster 8 - gray-green), from Morocco and Syria (Cluster 9 - dark green), and from USA and Pomarico, Italy (Cluster 5 - light green). All the others show a less significant grouping admixture.

\section{Discriminant analysis of principal components (DAPC)}

The DAPC analysis in Fig. 5 also supported the hypothesis of grouping the strains in 9 clusters as the best solution, according to the Bayesian Information Criterion.
Table 2 Poppr function statistics: number of strains for each population (N), MultiLocus genotypes (MLG) and expected ones (eMLG), eveness (E), Simpon's index (lambda) and Nei's genetic diversity (expected heterozygosity)

\begin{tabular}{lrrllll}
\hline Pseudomonas savastanoi pathovars & $\mathrm{N}$ & $\mathrm{MLG}$ & $\mathrm{eMLG}$ & $\mathrm{E} .5$ & lambda & Hexp \\
\hline savastanoi & 60 & 55 & 9.810206 & 0.905049 & 0.978889 & 0.640589 \\
fraxini & 11 & 11 & 10 & 1 & 0.909091 & 0.415931 \\
nerii & 10 & 9 & 9 & 0.9517 & 0.88 & 0.383704 \\
phaseolicola & 2 & 2 & 2 & 1 & 0.5 & 0.133333 \\
retacarpa & 1 & 1 & 1 & $\mathrm{NA}$ & 0 & 0 \\
Total & 84 & 78 & 9.88875 & 0.923356 & 0.985544 & 0.657298 \\
\hline
\end{tabular}




$\begin{array}{lllllll}0.3 & 0.25 & 0.2 & 0.15 & 0.1 & 0.05 & 0\end{array}$

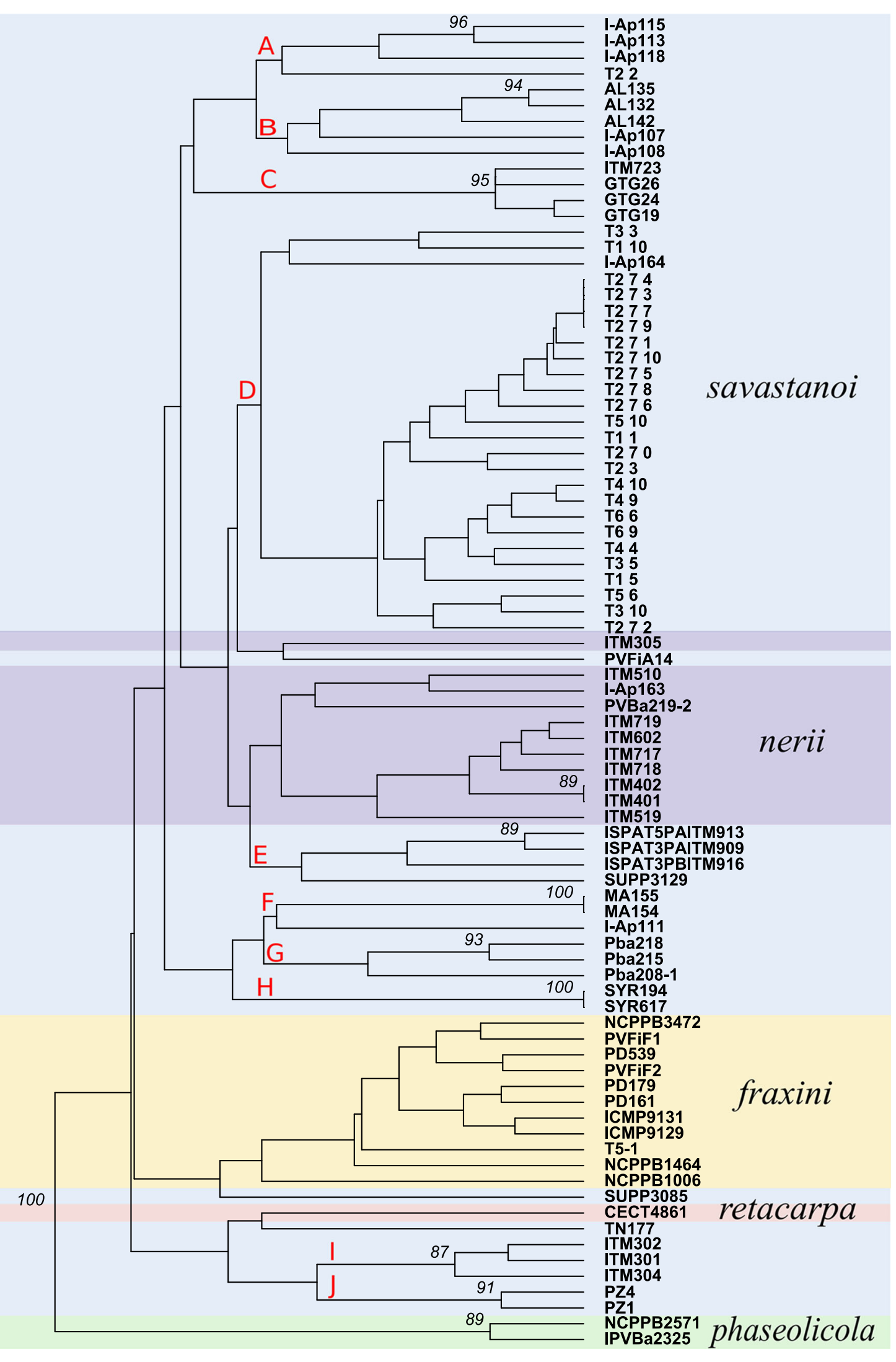




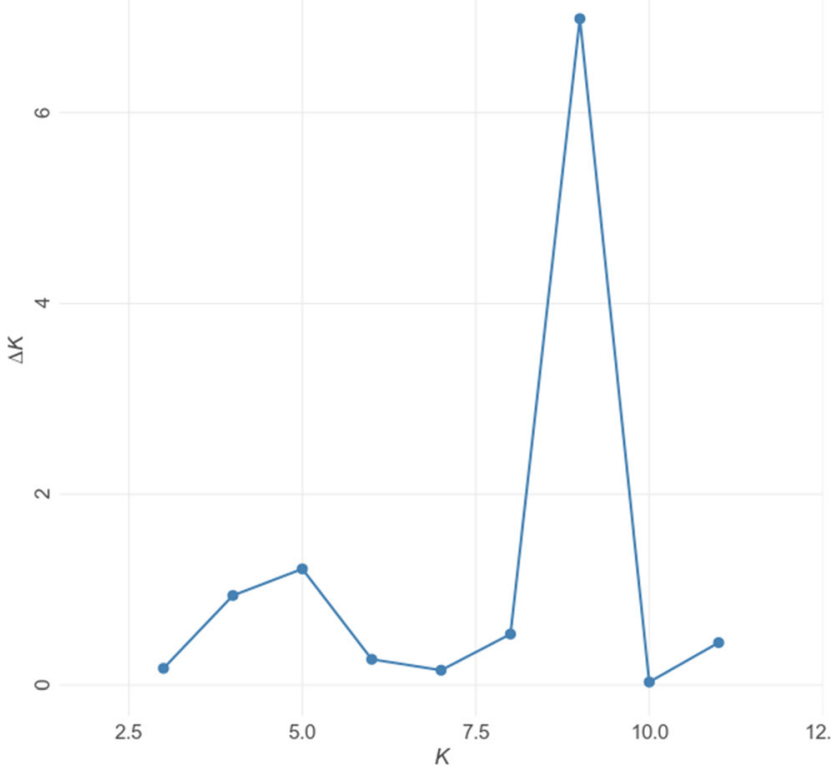

Fig. 3 Evanno's method showing the number of K groups that best represent the population structure of Pseudomonas savastanoi

The resulting scatterplot in Fig. 6 shows the distribution of the clusters on LD axes when 15 principal components were retained, and second and third linear discriminants were selected. Once again, the general structure of groups as reported from previous analytical approaches is conserved. Indeed, the strains belonging to pathovar fraxini cluster separately from all the others (group 5 - yellow), except for the strain NCPPB 1006, along with pathovar nerii (group 3 - grey) and phaseolicola (group 2 - light blue). The numerous strains of the pathovar savastanoi are scattered in many groups, with a more or less admixed composition, which is represented by the overlapping ellipses, descriptive of the same subgroups identified before. The DAPC posterior probability of assignment for each individual to the 9 groups is shown in Figure 7.

\section{Discussion}

Molecular approaches are often used to define the evolutionary history, the host adaptation, and the genetic diversity of a pathogen (Van Belkum et al. 2001; Scortichini et al. 2004; Wolska and Szwe 2012). Furthermore, they could reveal biological features influencing virulence, pathogenicity, and host specificity of the pathogen, helping to define sustainable control measures (Tibayrenc 2005, 2009; Vinatzer et al. 2014). The mentioned molecular tools that allow the discrimination between individuals of the same taxon according to host preferences, as well as time and geographic origin, are of particular significance in understanding the spread dynamics of bacterial plant pathogens. In this context, an MLVA assay was tested for the first time to infer the population structure within

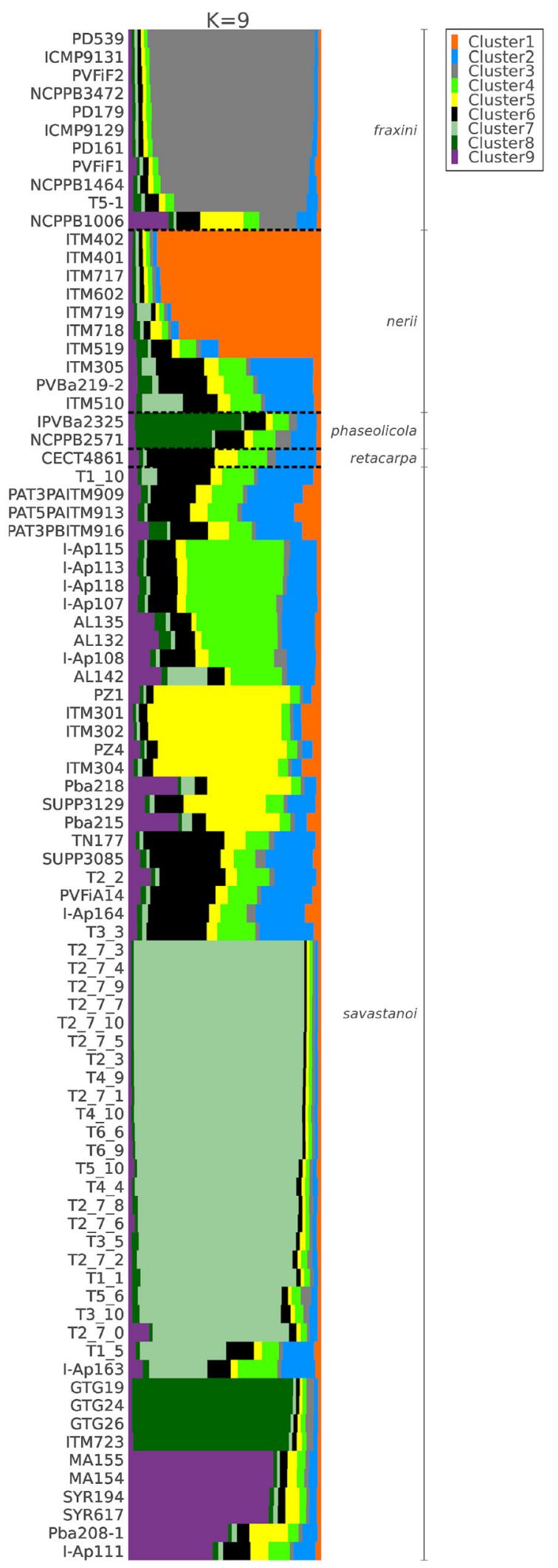

Fig. 4 Structure clump output for $\mathrm{K}=9$ following analysis of 84 isolates of Pseudomonas savastanoi, each strain represented by a single vertical line indicating its membership in each of $\mathrm{K}$ independent clusters. Pathovars indicated along the picture are separated by vertical black dashed lines 


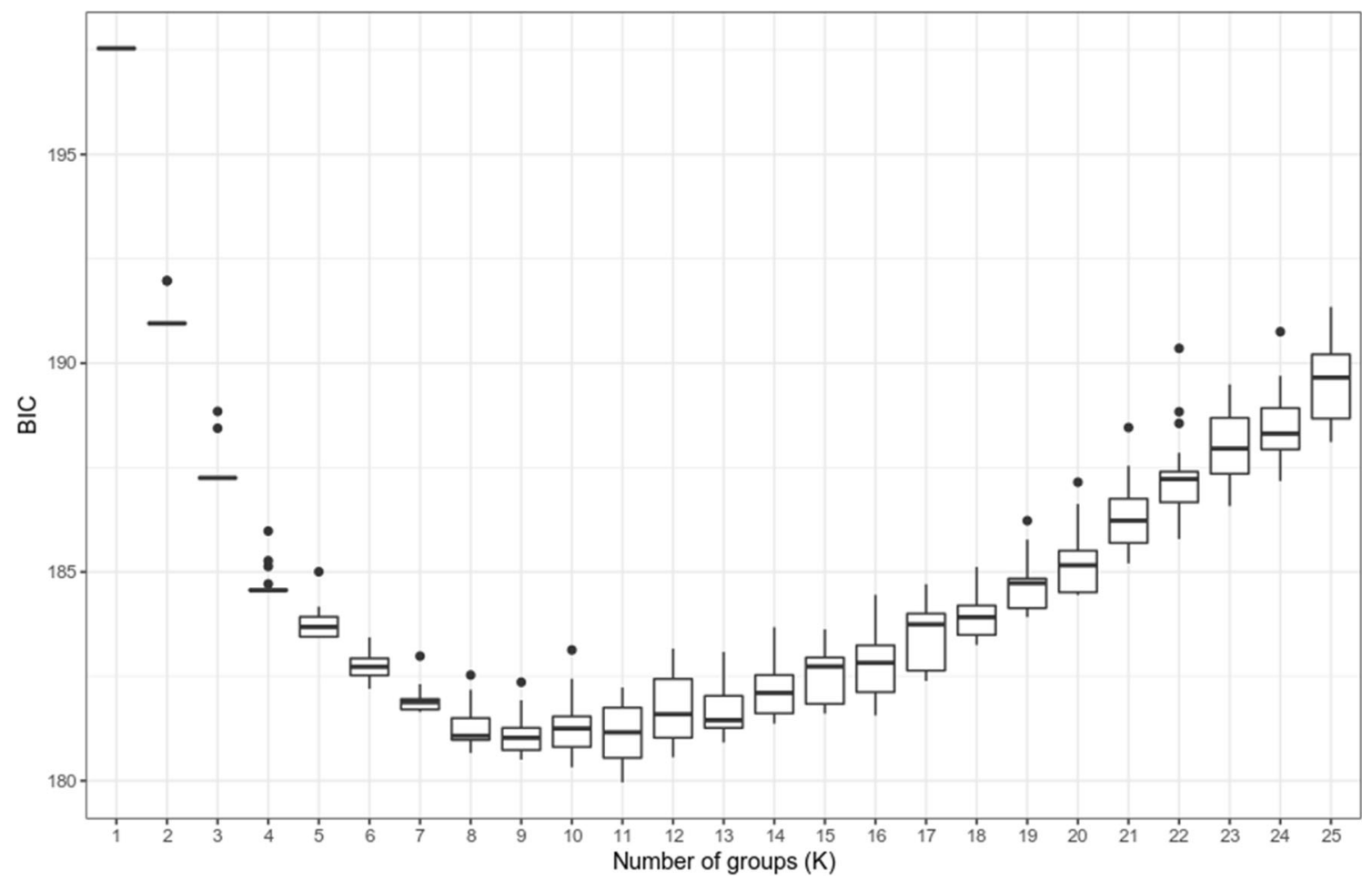

Fig. 5 Bayesian Information Criterion (BIC) curve for the k-means clustering of Pseudomonas savastanoi data set

Pseudomonas savastanoi pathovars. The 14 identified loci have proven to be able to provide enough information to disclose relationships among Pseudomonas savastanoi pathovars and strains.

As a first observation, the assay seems to be able to assign the samples to corresponding pathovars, as shown for the strains belonging to phaseolicola, nerii, and fraxini pathovars. Some exceptions, however, as the scattered distribution of strains belonging to pathovar savastanoi, indicate that the high proficiency of MLVA in revealing very slight differences between individuals makes this method only partially suitable to gauge this type of information. Other molecular methods, such as MLST, are more appropriate for this type of phylogenetic information and already available to the scientific community (Pitt 2010) .

Fig. 6 Scatterplot of genotypes in 9 groups according to DAPC. The individuals of the groups are distinguishable as in the present figure

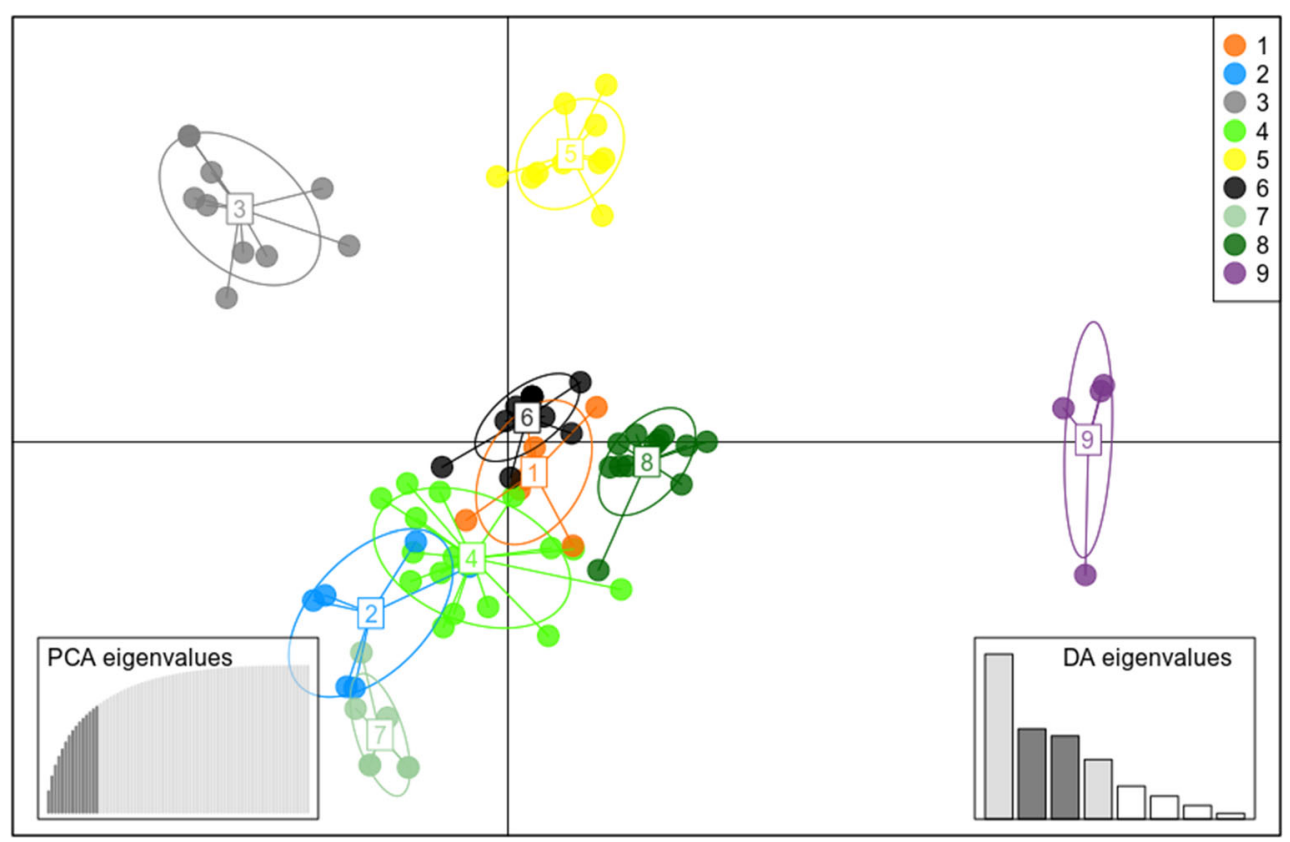


Fig. 7 The barplot shows the posterior probability of assignment of individuals in the 9 groups represented in different colours

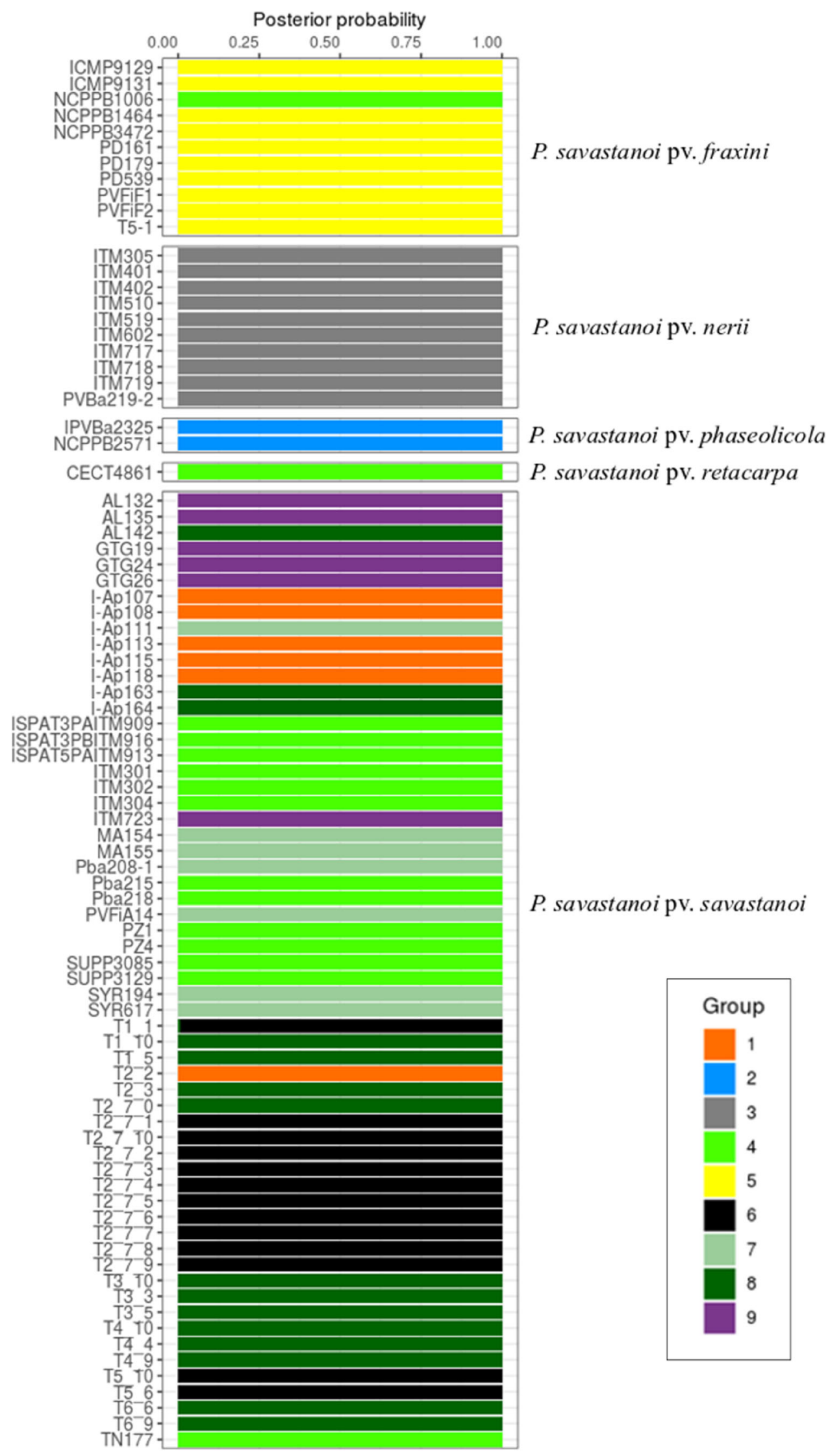


When the data are analysed as a whole, the MLVA assay was instead able to provide information about population structure and to further separate strains in groups. Data elaboration was approached using three analytical methods and their congruence was investigated. Interestingly, the preliminary approach of STRUCTURE, through Evanno's method, and DAPC, through the BIC criterion, both recommended nine clusters as the best fitting to the variability of the input data set. This grouping was rather consistent between the two methods, in particular with the groups including strains of the pathovars phaseolicola, fraxini and nerii that were clearly defined, as well as with the group of strains isolated from a single orchard in Viterbo. About the other groups, STRUCTURE provided less clear results as demonstrated by strong admixture in the posterior assignment to these groups. DAPC, as expected from its ability to maximize variance between groups, assigned the individuals to the groups more sharply. The hierarchical clustering based on Bruvo's distance provided detailed results and a higher number of possible clusters. This suggests an interesting connection between clusters and both geographical origin of the strains and host plant species.

In any case, the overall framework depicted in this study indicates a large amount of genetic variability in Pseudomonas savastanoi in general and, more specifically, for the pathovar savastanoi. A first explanation resides in the heterogeneity of the collection analyzed, which included strains of worldwide origin, from 13 different countries, and isolated along a time span of more than 50 years. It is a further confirmation that MLVA, relying on genetic elements with a particularly high rate of mutation, finds its ultimate application in depicting more specific situations, such as, typically, clonal outbreaks and epidemics.

This leads to another aspect of this research, which concerns the analysis of strains isolated from knots concurrently collected from 10 olive plants in a small orchard (with a surface less than 1 ha wide) in Viterbo and from different knots of a single plant in the same orchard. In this scenario, if the disease would have been related to an outbreak from a single infective event, it would have been also logical to assume a substantial genetic homogeneity among its isolates. Conversely, in our case the level of genetic variability observed was still relatively high, even from knots collected on a single plant. This could in turn be explained by acknowledging that $P$. savastanoi pv. savastanoi is not an epidemic but an endemic pathogen, widespread in Italy for centuries. Such a long history of coevolution between the pathogen and its host plant has probably led to the differentiation of uncountable genotypes so that even on a single plant, as for plant T2.7, multiple infections by different genotypes commonly occurs. Furthermore, few isolates from other plants in the orchard are included in the cluster of the isolates from this single plant, just as few individuals from this single plant matched groups of isolates from other plants. This great admixture on a very confined plot might be explained by a human-mediated transmission of the bacterial infection through infected tools during pruning from a plant to another.

In conclusion, this MLVA assay developed and applied for the first time to Pseudomonas savastanoi, has proven so responsive that even isolates from a single plant could be distinguished. Consequently, the most consistent goal of this method towards an endemic pathogen as Pseudomonas savastanoi pv. savastanoi should be the analysis of very specific situations. The method could be valuable to investigate biological facets such as how single genotypes infect and colonize tissues and organs of the same plant. Moreover, it could be used to evaluate possible interactions between strains colonizing the same tissue, or even to reconstruct microevolutive drifts over time in connection to changes in environmental conditions or in orchard management.

Acknowledgements The research was carried out in the frame of the MIUR (Ministry for education, University and Research) initiative "Department of Excellence" (Law 232/2016). We thank the CIHEAM Mediterranean Agronomic Institute of Bari for funding the $\mathrm{PhD}$ grant to Yaseen Jundi Rahi within HiSpro Project (High Studies Programme for Iraqi officials at Italian Academic Institutions) jointly with the Iraqi Ministry of Agriculture.

\section{Compliance with ethical standards}

Conflict of interest All the authors declare that they have no conflict of interest.

Ethics approval This article does not contain any studies with human participants or animals performed by any of the authors.

\section{References}

Achtman M (2008) Evolution, population structure, and phylogeography of genetically monomorphic bacterial pathogens. Annu Rev Microbiol 62:53-70. https://doi.org/10.1146/annurev.micro.62. 081307.162832

Altschul SF, Gish W, Miller W et al (1990) Basic local alignment search tool. J Mol Biol 215:403-410. https://doi.org/10.1016/S00222836(05)80360-2

Bartoli C, Lamichhane JR, Berge O et al (2015) Mutability in Pseudomonas viridiflava as a programmed balance between antibiotic resistance and pathogenicity. Mol Plant Pathol 16:860-869. https://doi.org/10.1111/mpp.12243

Bennasar A, Mulet M, Lalucat J, García-Valdés E (2010) PseudoMLSA: a database for multigenic sequence analysis of Pseudomonas species. BMC Microbiol 10:118. https://doi.org/10.1186/1471-2180$10-118$

Benson G (1999) Tandem repeats finder: a program to analyze DNA sequences. Nucleic Acids Res 27:573-580. https://doi.org/10. 1093/nar/27.2.573

Bergsma-Vlami M, Martin W, Koenraadt H et al (2012) Molecular typing of Dutch isolates of Xanthomonas arboricola pv. pruni isolated from ornamental cherry laurel. J Plant Pathol 94:S1.29-S1.35. https://doi.org/10.4454/jpp.v94i1sup.006 
Bradbury JF (1986) Guide to plant pathogenic Bacteria; CAB international mycological institute. J Bradbury-1986-334 p 332

Bühlmann A, Dreo T, Rezzonico F et al (2014) Phylogeography and population structure of the biologically invasive phytopathogen Erwinia amylovora inferred using minisatellites. Environ Microbiol 16:2112-2125. https://doi.org/10.1111/1462-2920.12289

Buonaurio R, Moretti C, Da Silva DP et al (2015) The olive knot disease as a model to study the role of interspecies bacterial communities in plant disease. Front Plant Sci 6. https://doi.org/10.3389/fpls.2015. 00434

Cangelosi GA, Freeman RJ, Lewis KN et al (2004) Evaluation of a highthroughput repetitive-sequence-based PCR system for DNA fingerprinting of Mycobacterium tuberculosis and Mycobacterium avium complex strains. J Clin Microbiol 42:2685-2693. https://doi.org/10. 1128/JCM.42.6.2685-2693.2004

Cesbron S, Pothier J, Gironde S et al (2014) Development of multilocus variable-number tandem repeat analysis (MLVA) for Xanthomonas arboricola pathovars. J Microbiol Methods 100:84-90. https://doi. org/10.1016/j.mimet.2014.02.017

Ciarroni S, Gallipoli L, Taratufolo MC et al (2015) Development of a multiple loci variable number of tandem repeats analysis (MLVA) to unravel the intra-pathovar structure of Pseudomonas syringae pv. actinidiae populations worldwide. PLoS One 10:e135310. https:// doi.org/10.1371/journal.pone.0135310

Cinelli T, Marchi G, Cimmino A et al (2014) Heterogeneity of Pseudomonas savastanoi populations infecting Myrtus communis in Sardinia (Italy). Plant Pathol 63:277-289. https://doi.org/10. 1111/ppa.12096

Davis EW, Weisberg AJ, Tabima JF et al (2016) Gall-ID: tools for genotyping gall-causing phytopathogenic bacteria. PeerJ 4:e2222. https://doi.org/10.7717/peerj.2222

Della Coletta-Filho H, Takita MA, De Souza AA et al (2001) Differentiation of strains of Xylella fastidiosa by a variable number of tandem repeat analysis. Appl Environ Microbiol 67:4091-4095. https://doi.org/10.1128/AEM.67.9.4091-4095.2001

Dray S, Dufour AB (2007) The ade4 package: implementing the duality diagram for ecologists. J stat Softw 22:1-20. https://doi.org/10. 18637 /jss.v022.i04

Dworkin M (2006) The prokaryotes - Vol. 6: Proteobacteria: gamma subclass. Springer, 3rd edn. Springer-Verlag New York, New York

Ee CS, Ismail A, Banga Singh KK (2017) Chapter 3.7. Multiple-locus variable-number tandem repeat analysis (MLVA) for bacterial typing. In: sustainable diagnostics for low resource areas. Perpustakaan Negara, Malaysia

Evanno G, Regnaut S, Goudet J (2005) Detecting the number of clusters of individuals using the software STRUCTURE: a simulation study. Mol Ecol 14:2611-2620. https://doi.org/10.1111/j.1365-294X. 2005.02553.x

Francis RM (2017) pophelper: an R package and web app to analyse and visualize population structure. Mol Ecol Resour 17:27-32. https:// doi.org/10.1111/1755-0998.12509

Garcia De Los Rios JE (1999) Retama sphaerocarpa (L.) Boiss., a new host of Pseudomonas savastanoi. Phytopathol Mediterr 38:54-60

Gardan L, Bollet C, Ghorrah MA et al (1992) DNA relatedness among the pathovar strains of Pseudomonas syringae subsp. savastanoi Janse (1982) and proposal of Pseudomonas savastanoi sp. nov. Int J Syst Bacteriol 42:606-612. https://doi.org/10.1099/00207713-424-606

Gemayel R, Vinces MD, Legendre M, Verstrepen KJ (2010) Variable tandem repeats accelerate evolution of coding and regulatory sequences. Annu Rev Genet 44:445-477. https://doi.org/10.1146/ annurev-genet-072610-155046
Gironde S, Manceau C (2012) Housekeeping gene sequencing and multilocus variable-number tandem-repeat analysis to identify subpopulations within Pseudomonas syringae pv. maculicola and Pseudomonas syringae pv. tomato that correlate with host specificity. Appl Environ Microbiol 78:3266-3279. https://doi.org/10.1128/ AEM.06655-11

Grissa I, Bouchon P, Pourcel C, Vergnaud G (2008) On-line resources for bacterial micro-evolution studies using MLVA or CRISPR typing. Biochimie 90:660-668. https://doi.org/10.1016/j.biochi.2007.07. 014

Grünwald NJ, Goss EM (2011) Evolution and population genetics of exotic and re-emerging pathogens: novel tools and approaches. Annu Rev Phytopathol 49:249-267. https://doi.org/10.1146/ annurev-phyto-072910-095246

Grünwald NJ, Everhart SE, Knaus BJ, Kamvar ZN (2017) Best practices for population genetic analyses. Phytopathology 107:1000-1010. https://doi.org/10.1094/PHYTO-12-16-0425-RVW

Guinard J, Latreille A, Guérin F et al (2017) New multilocus variablenumber tandem-repeat analysis (MLVA) scheme for fine-scale monitoring and microevolution-related study of Ralstonia pseudosolanacearum phylotype I populations. Appl environ Microbiol 83. https://doi.org/10.1128/AEM.03095-16

Hartl DL, Clark AG (2007) Principles of population genetics, fourth Edi. Sunderland, Massachusetts

Iacobellis NS (2001) Olive knot. Encycl Plant Pathol:713-715

Iacobellis NS, Caponero A, Evidente A (1998) Characterization of Pseudomonas syringae ssp. savastanoi strains isolated from ash. Plant Pathol 47:73-83. https://doi.org/10.1046/j.1365-3059.1998. 00202.x

Janse JD (1982) Pseudomonas syringae subsp. savastanoi (ex smith) subsp. nov., nom. Rev., the bacterium causing excrescences on Oleaceae and Nerium oleander L. Int J Syst Bacteriol 32:166169. https://doi.org/10.1099/00207713-32-2-166

Jombart T (2008) adegenet: a R package for the multivariate analysis of genetic markers. Bioinformatics 24:1403-1405. https://doi.org/10. 1093/bioinformatics/btn129

Jombart T, Devillard S, Balloux F (2010) Discriminant analysis of principal components: a new method for the analysis of genetically structured populations. BMC Genet 11:94. https://doi.org/10.1186/ 1471-2156-11-94

Kamvar ZN, Tabima JF, Grünwald NJ (2014) Poppr: an R package for genetic analysis of populations with clonal, partially clonal, and/or sexual reproduction. PeerJ 2013:1-14. https://doi.org/10.7717/ peerj. 281

Kamvar ZN, Brooks JC, Grünwald NJ (2015) Novel R tools for analysis of genome-wide population genetic data with emphasis on clonality. Front Genet 6. https://doi.org/10.3389/fgene.2015.00208

Kassambara A, Mundt F (2017) Package "factoextra" for R: extract and visualize the results of multivariate data analyses. R Packag. version, In http://www.sthda.com/english/rpkgs/factoextra\%0ABugReports

Krid S, Rhouma A, Quesada JM et al (2009) Delineation of Pseudomonas savastanoi pv. savastanoi strains isolated in Tunisia by randomamplified polymorphic DNA analysis. J Appl Microbiol 106:886894. https://doi.org/10.1111/j.1365-2672.2008.04058.x

Le Flèche P, Jacques I, Grayon M et al (2006) Evaluation and selection of tandem repeat loci for a Brucella MLVA typing assay. BMC Microbiol 6. https://doi.org/10.1186/1471-2180-6-9

Li W, Raoult D, Fournier PE (2009) Bacterial strain typing in the genomic era. FEMS Microbiol Rev 33:892-916. https://doi.org/10.1111/ j.1574-6976.2009.00182.x

Lindstedt BA (2005) Multiple-locus variable number tandem repeats analysis for genetic fingerprinting of pathogenic bacteria. 
Electrophoresis 26:2567-2582. https://doi.org/10.1002/elps. 200500096

López MM, Quesada JM, Penyalver R et al (2008) Current technologies for Pseudomonas spp. and Ralstonia solanacearum detection and molecular typing. In: Pseudomonas syringae pathovars and related pathogens - identification. Epidemiology and Genomics, Springer Netherlands, pp 3-19

Marchi G, Cinelli T, Surico G (2011) A review on Pseudomonas savastanoi genetic traits involved in disease development and in symptom induction. In: Schena L, Agosteo GE, Cacciola S.O. (eds) olive diseases and disorders. Chapter 6, pp 117-141. https:// doi.org/10.13140/2.1.2408.0328

Marsh JW, O'Leary MM, Shutt KA et al (2006) Multilocus variablenumber tandem-repeat analysis for investigation of Clostridium difficile transmission in hospitals. J Clin Microbiol 44:2558-2566. https://doi.org/10.1128/JCM.02364-05

Moretti C, Cortese C, da Silva DP et al (2014) Draft genome sequence of Pseudomonas savastanoi pv. savastanoi strain DAPP-PG 722, isolated in Italy from an olive plant affected by knot disease. Genome Announc 2. https://doi.org/10.1128/genomeA.00864-14

Moretti C, Vinatzer BA, Onofri A et al (2017) Genetic and phenotypic diversity of Mediterranean populations of the olive knot pathogen, Pseudomonas savastanoi pv. savastanoi. Plant Pathol 66:595-605. https://doi.org/10.1111/ppa.12614

Mugnai L, Giovannetti L, Ventura S, Surico G (1994) The grouping of strains of Pseudomonas syringae subsp. savastanoi by DNA restriction fingerprinting. J Phytopathol 142:209-218. https://doi.org/10. 1111/j.1439-0434.1994.tb04531.x

N'Guessan CA, Brisse S, Le Roux-Nio AC et al (2013) Development of variable number of tandem repeats typing schemes for Ralstonia solanacearum, the agent of bacterial wilt, banana Moko disease and potato brown rot. J Microbiol Methods 92:366-374. https:// doi.org/10.1016/j.mimet.2013.01.012

Noller AC, McEllistrem MC, Pacheco AGF et al (2003) Multilocus variable-number tandem repeat analysis distinguishes outbreak and sporadic Escherichia coli O157:H7 isolates. J Clin Microbiol 41: 5389-5397. https://doi.org/10.1128/JCM.41.12.5389-5397.2003

Oliveira EJ, Pádua JG, Zucchi MI et al (2006) Origin, evolution and genome distribution of microsatellites. Genet Mol Biol 29:294-307

Penyalver R, García A, Ferrer A et al (2000) Detection of Pseudomonas savastanoi pv. savastanoi in olive plants by enrichment and PCR. Appl Environ Microbiol 66:2673-2677. https://doi.org/10.1128/ aem.66.6.2673-2677.2000

Pérez-Martínez I, Zhao Y, Murillo J et al (2008) Global genomic analysis of Pseudomonas savastanoi pv. savastanoi plasmids. J Bacteriol 190:625-635. https://doi.org/10.1128/JB.01067-07

Pitt TL (2010) Molecular epidemiology of microorganisms: methods and protocols. J Hosp Infect 75:247. https://doi.org/10.1016/j.jhin.2010. 02.002

Poulin L, Grygiel P, Magne M et al (2015) New multilocus variablenumber tandem-repeat analysis tool for surveillance and local epidemiology of bacterial leaf blight and bacterial leaf streak of rice caused by Xanthomonas oryzae. Appl Environ Microbiol 81:688698. https://doi.org/10.1128/AEM.02768-14

Pritchard JK, Stephens M, Donnelly P (2000) Inference of population structure using multilocus genotype data. Genetics 155:945-959

Pruvost O, Magne M, Boyer K et al (2014) A MLVA genotyping scheme for global surveillance of the citrus pathogen Xanthomonas citri pv citri suggests a worldwide geographical expansion of a single genetic lineage PLoS One:9. https://doi.org/10.1371/journal.pone. 0098129

R Core Team (2018) R: A Language and Environment for Statistical Computing
Ramos C, Matas IM, Bardaji L et al (2012) Pseudomonas savastanoi pv. savastanoi: some like it knot. Mol Plant Pathol 13:998-1009. https://doi.org/10.1111/j.1364-3703.2012.00816.x

Reinar W, Knutsen J, Jentoft S et al (2018) Evolutionary adaptability linked to length variation in short genic tandem repeats. https://doi. org/10.1101/310045

Rocha EPC (2003) DNA repeats lead to the accelerated loss of gene order in bacteria. Trends Genet 19:600-603. https://doi.org/10.1016/j.tig. 2003.09.011

Rodríguez-Palenzuela P, Matas IM, Murillo J et al (2010) Annotation and overview of the Pseudomonas savastanoi pv. savastanoi NCPPB 3335 draft genome reveals the virulence gene complement of a tumour-inducing pathogen of woody hosts. Environ Microbiol 12: 1604-1620. https://doi.org/10.1111/j.1462-2920.2010.02207.x

Saunders NJ, Jeffries AC, Peden JF et al (2000) Repeat-associated phase variable genes in the complete genome sequence of Neisseria meningitidis strain MC58. Mol Microbiol 37:207-215. https://doi. org/10.1046/j.1365-2958.2000.02000.x

Scortichini M, Rossi MP, Salerno M (2004) Relationship of genetic structure of Pseudomonas savastanoi pv. savastanoi populations from Italian olive trees and patterns of host genetic diversity. Plant Pathol 53:491-497. https://doi.org/10.1046/j.0032-0862.2004.01051.x

Sisto A, Morea M, Baruzzi F, Palumbo G (2002) Differentiation of Pseudomonas syringae subsp. savastanoi strains isolated from various host plants by restriction fragment length polymorphism. Phytopathol Mediterr 41:63-71

Sisto A, Cipriani MG, Tegli S et al (2007) Genetic characterization by fluorescent AFLP of Pseudomonas savastanoi pv. savastanoi strains isolated from different host species. Plant Pathol 56:366372. https://doi.org/10.1111/j.1365-3059.2007.01567.x

Tibayrenc M (2005) Bridging the gap between molecular epidemiologists and evolutionists. Trends Microbiol 13:575-580. https://doi.org/10. 1016/j.tim.2005.09.004

Tibayrenc M (2009) Microbial molecular epidemiology: an overview. Methods Mol Biol 551:1-12

Treangen TJ, Abraham AL, Touchon M, Rocha EPC (2009) Genesis, effects and fates of repeats in prokaryotic genomes. In: FEMS Microbiology Reviews. pp 539-571. https://doi.org/10.1111/j. 1574-6976.2009.00169.x

van Belkum A, Scherer S, van Leeuwen W et al (1997) Variable number of tandem repeats in clinical strains of Haemophilus influenzae. Infect Immun 65:5017-5027

van Belkum A, Scherer S, van Alphen L, Verbrugh H (1998) Shortsequence DNA repeats in prokaryotic genomes. Microbiol Mol Biol Rev 62:275-293

van Belkum A, Struelens M, De Visser A et al (2001) Role of genomic typing in taxonomy, evolutionary genetics, and microbial epidemiology. Clin Microbiol Rev 14:547-560. https://doi.org/10.1128/ CMR.14.3.547-560.2001

Vernière C, Bui Thi Ngoc L, Jarne P et al (2014) Highly polymorphic markers reveal the establishment of an invasive lineage of the citrus bacterial pathogen Xanthomonas citri pv. citri in its area of origin. Environ Microbiol 16:2226-2237. https://doi.org/10.1111/14622920.12369

Vieira MLC, Santini L, Diniz AL, Munhoz C de F (2016) Microsatellite markers: what they mean and why they are so useful. Genet Mol Biol 39:312-328. https://doi.org/10.1590/1678-4685-GMB-20160027

Vinatzer BA, Monteil CL, Clarke CR (2014) Harnessing population genomics to understand how bacterial pathogens emerge, adapt to crop hosts, and disseminate. Annu Rev Phytopathol 52:19-43. https:// doi.org/10.1146/annurev-phyto-102313-045907 
Völksch B, Weingart H (1997) Comparison of ethylene-producing Pseudomonas syringae strains isolated from kudzu (Pueraria lobata) with Pseudomonas syringae pv. phaseolicola and Pseudomonas syringae pv. glycinea. Eur J Plant Pathol 103:795802. https://doi.org/10.1023/A:1008686609138

Wolska K, Szwe P (2012) Genotyping techniques for determining the diversity of microorganisms. Genetic Diversity in Microorganisms. InTechOpen, In

Young JM (1978) A proposed nomenclature and classification for plant pathogenic bacteria. New Zeal J Agric Res 21:153-177. https://doi. org/10.1080/00288233.1978.10427397

Zaluga J, Stragier P, Van Vaerenbergh J et al (2013) Multilocus variablenumber-tandem-repeats analysis (MLVA) distinguishes a clonal complex of Clavibacter michiganensis subsp. michiganensis strains isolated from recent outbreaks of bacterial wilt and canker in Belgium. BMC Microbiol 13. https://doi.org/10.1186/1471-218013-126

Zhao S, Poulin L, Rodriguez-R LM et al (2012) Development of a variable number tandem repeats typing scheme for the bacterial rice pathogen Xanthomonas oryzae pv. oryzicola. Phytopathology 102: 948-956. https://doi.org/10.1094/PHYTO-04-12-0078-R

Publisher's note Springer Nature remains neutral with regard to jurisdictional claims in published maps and institutional affiliations. 